\title{
Connecting Classroom to Community Through Photovoice: Pedagogical Implications
}

\author{
İnci Yilmazli Trout, Beatrix Perez, and M. Candace Christensen
}

\begin{abstract}
This paper explores the pedagogical implications of using arts-based research in an advanced community practice course in a Master of Social Work program. Per the course design, graduate students implemented a photovoice project with undergraduate students focusing on transforming campus rape culture. At the end of the project, graduate students wrote reflection papers that constitute the data for this paper. The data analysis resulted in three categories: enhancing the learning of content, understanding the role of a social worker in macro-level practice, and engaging with the community.
\end{abstract}

The premise of social work education builds on values, skills, and qualities necessary to equip future social workers as critical, socially responsible citizens who contribute to the well-being of the society (Maistry, 2012). The nature of social work involves engagement with vulnerable and underserved communities, which requires value-based, collective approaches to embracing social work knowledge and relationship building, collaboration, and mobilization (Dixon \& Hoatson, 1999; Barron \& Taylor, 2010). Considering the skills social workers need, their education should include new ways of addressing each component through hands-on experience. The goal is to not only teach content, but also use innovative approaches to research with communities. The focus of using photovoice in an advanced community practice course was to enhance research skills, raise awareness of social issues, and foster students' learning.

Prior studies have shown how incorporating a participatory research project as part of coursework provides an opportunity to engage with the community (Holley, Risley-Curtiss, Stott, Jackson, \& Nelson, 2007; Lucero, 2015). This engagement is an essential aspect of social work education. Expanding on this premise, the present study explored the learning and research implications of using arts-based research $(A B R)$ as a method for teaching community practice. The researchers used a constructivist paradigm in the design of this study and a grounded theory approach for the data analysis. As part of a Master of Social Work (MSW) program, one faculty member (and author of this paper) transformed an advanced community practice course into the implementation and evaluation of a photovoice project. The topic for the project was "Transforming Campus Rape Culture." The research question guiding this study was, "What role does ABR play as a pedagogical tool for instructing MSW students in community practice?" 


\section{Background and Context}

\section{Community Practice}

The Council on Social Work Education (CSWE) accredits Social Work programs across the United States. This accrediting body established Educational Policy Standards (EPAS) or competencies to ensure that social work curricula meet educational outcomes or practice behaviors defined by the Council (Council on Social Work Education, 2015). Educators develop competency assignments to help students learn specific practice behaviors and skills. The EPAS provides the basis on which to assess skills that demonstrate professional social work practice. Therefore, social work program curricula are constructed to ensure students learn social work values, skills, and knowledge necessary for ethical and culturally competent practice.

The community practice aspect of social work education focuses on teaching students the values, knowledge, and skills necessary to build relationships with communities, help communities to identify issues they wish to change, and to harness community strengths and develop resources to create the change (Ohmer, Reisch, \& Weil, 2013). As part of a master's level social work curriculum, students learn how to build relationships with(in) communities, design and implement interventions, and evaluate practice outcomes (Ohmer et al., 2013). Therefore, the faculty member, who is one of the authors of this paper, designed an "Advanced Community Practice" course to provide an opportunity for students not only to learn how to build relationships, but also how to implement an intervention, and evaluate the outcomes. The photovoice project was the primary competency assignment linked to specific social work practice behaviors associated with macro-level community practice. Competencies associated with this course included the following: a) understanding diverse and oppressed populations, b) engaging with diverse groups in various settings, understanding ethical decision making to address community dilemmas, and c) engaging in dialogue with stakeholders, organizations, and communities as partners in the change process. Other competencies required social work students to gain experience with constructing and evaluating interventions, advocating for policy change, providing leadership in collaboration with clients and stakeholders, and understanding the impact of community participatory action research.

Using ABR methodology and methods to teach community practice combines the processes of generating community-based data in the form of art artifacts while helping the community to organize around identified issues (Minkler, 2000). In alignment with this purpose, the instructor required students to conduct a photovoice research project focused on transforming campus rape culture and to evaluate the impact on the campus community. As a tool for teaching community practice, photovoice teaches students how to build relationships with a given community, collect multiple forms of data that illustrate community concerns, engage the community in the analysis and presentation of the data, and evaluate the impact the photovoice project has on the stakeholders who view the photographs and read the narratives (Wang \& Burris, 1997; Wang, 1999). 


\section{Arts-Based Research as a Pedagogical Tool}

$\mathrm{ABR}$ is becoming more commonly used in qualitative research as a way of generating knowledge and conveying an understanding that draws from creative arts in research contexts (Schell, Ferguson, Hamoline, Shea, \& Thomas-Maclean, 2009; Leavy, 2018). Scholars and practitioners consider ABR as methodological tools that researchers can use in all phases of social research, including data collection, analysis, interpretation, and representation (Leavy, 2009). Visual methods, mainly, are receiving attention from qualitative researchers in the social sciences (Holm, Sahlström, \& Zilliacus, 2018). Human understanding can be increased with the use of visual arts, as artistic images allow us to access knowledge that is hidden or ignored. Also, through these images, new ways of seeing or doing can be achieved which result in influencing human thinking or behaviors (Weber, 2008). More importantly, arts-based visual studies have the potential to provoke critical questions and move people (Finley, 2008). While using artistic ways of knowing allows for accessing human experiences deeply, it also strengthens the impact of the study as the art-in this case, the photographs—speak without words and create an emotional effect on the audience. In other words, aesthetic knowing complements the scientific aspect of the research in a creative way (McNiff, 2018). Artistic means of sharing human experiences eliminates an objective view of the data and privileges the perspective of the person who has taken the photographs (Cooper, Sorensen, \& Yarbrough, 2017; Chio \& Fandt, 2007).

Photovoice, a visual method, strives to generate positive change in communities by engaging community members in articulating their point of view on given phenomena through photographs, narratives, and dialogue with stakeholders (Wang \& Burris, 1997; Wang, 1999). These characteristics of photovoice make it a perfect tool to apply in social work education. Photovoice method involves a lead researcher recruiting a small group of community members to document their perceptions and experiences about their community by taking photographs and describing the pictures, then displaying the prints for stakeholders. After the public display, the community members critically reflect on the data they presented and the new data they gathered from the stakeholders' response to the photographs. This critical reflection is used to develop a tangible list of solutions targeting the problem (Wang \& Burris, 1997; Wang, 1999).

\section{Methodology}

The design of this study engaged a constructivist perspective, which infuses the design of a study with a methodical examination of how communities construct knowledge according to context, perceptions, and experiences (Guba \& Lincoln, 1994). This perspective situates an individual's unique perceptions and experiences as legitimate sources of knowledge that can be used to further our understanding of a given phenomenon. It also examines how our social context contributes to the invention of social norms and customs, which brings into question what is considered "normal" and counters with a vision for supporting multiple truths. The current study is qualitative in design with the purpose of exploring the learning experiences of MSW students who recruited and trained participants in using photovoice to generate knowledge, dialogue, and activity focused on addressing campus rape culture. The data artifacts 
included the coursework produced by students from courses taught in the Spring 2017 and Fall 2017 semesters. The data analysis methods were grounded theory techniques as described by Charmaz (2014).

\section{Participants}

Fifty-five graduate students (women $n=47$, men $n=8$ ) who are enrolled in an Advanced Community Practice course in the Master of Social Work (MSW) program at a Hispanic serving, state university in the south region of the U.S. volunteered to participate in the study. As part of the requirements for the course, MSW students conducted a photovoice project within the university community where they recruited undergraduate students to be the participants of the photovoice project. Considering the nature of the advanced community practice course in which students are expected to learn how to engage with and organize a community, graduate participants took on the researcher role to conduct the photovoice project with members from the university community. The university internal review board (IRB) determined that this study is considered nonregulated research. MSW students generated the data used for this study as part of a coursework requirement. The researchers analyzed the data with the intention of examining the impact the course curriculum has on students. The names of students mentioned in this paper are pseudonyms.

\section{The Course Design}

This paper focused on the pedagogical process involved with guiding three classes through the implementation and evaluation of three photovoice projects. Each project consisted of multiple phases. In the first phase, the MSW students reached out to the undergraduate student population of the university to explain the purpose of the research project and recruit them as voluntary participants. After the recruitment phase, the MSW students held an information session to train the undergraduates on how to take photographs that illustrate a) how they perceive campus sexual violence and b) how they believe the campus community could transform the campus culture to support the prevention of the perpetration of sexual violence. Also, the MSW students provided training on the goals of photovoice, ethical issues related to taking the photographs, and how to compose images that convey both a symbolic message about sexual violence and incorporate technical aspects of photography. The MSW students gave the undergraduate participants three weeks to complete their photo taking and move to the next phase of the project, which was a focus group session.

The instructor of the course led the focus group discussion and the MSW students observed how to lead the undergraduate students through a critical analysis of the photographs. The instructor led the focus group discussion because the instructor has years of focus group facilitation experience. From a learning perspective, having the students observe the focus group process is valuable as a scaffolding tool (Vygotsky, 1978). The instructor structured the focus group discussion on how to use ABR to generate local knowledge about how a community perceives a given topic. During this session, undergraduate students observed, discussed, and analyzed all the photographs produced for this project. For discussion, the instructor used the SHOWeD method which stands for: what do you See here? What is really Happening? How does this relate to Our lives? Why does this problem exist? 
What can we Do about it? (Wang, Morrel-Samuels, Hutchison, Bell, \& Pestronk, 2004). Then, the instructor invited the undergraduate students to write a caption for their photos based on the SHOWeD prompts. Each MSW student wrote field notes as to what they heard and observed during the focus group discussion. Next, the focus group participants, MSW students, and instructor discussed logistics for how they would exhibit photos at a public event at the end of the semester.

After discussing these logistics, the instructor led the MSW students through a group discussion about their observations from the focus group. One MSW student took notes on details from the class group discussion. After this discussion, the instructor showed the students how to use the focus group data to discover themes that emerged from the participant discussion of the photographs. The instructor connected these themes to a constructivist understanding of how the undergraduate student participants perceive campus sexual violence.

Through social media, press releases, and flyers, the MSW students widely publicized the final exhibit with the goal of reaching as many people as possible to raise awareness or educate them on the subject matter. For the final phase, the MSW students developed and implemented a mixed methods survey to evaluate how the photovoice exhibit attendees perceived and experienced the exhibit. Figures 1 and 2 are examples of photographs and captions generated by the undergraduate students. Figure 1 demonstrates how one student perceives rape culture:

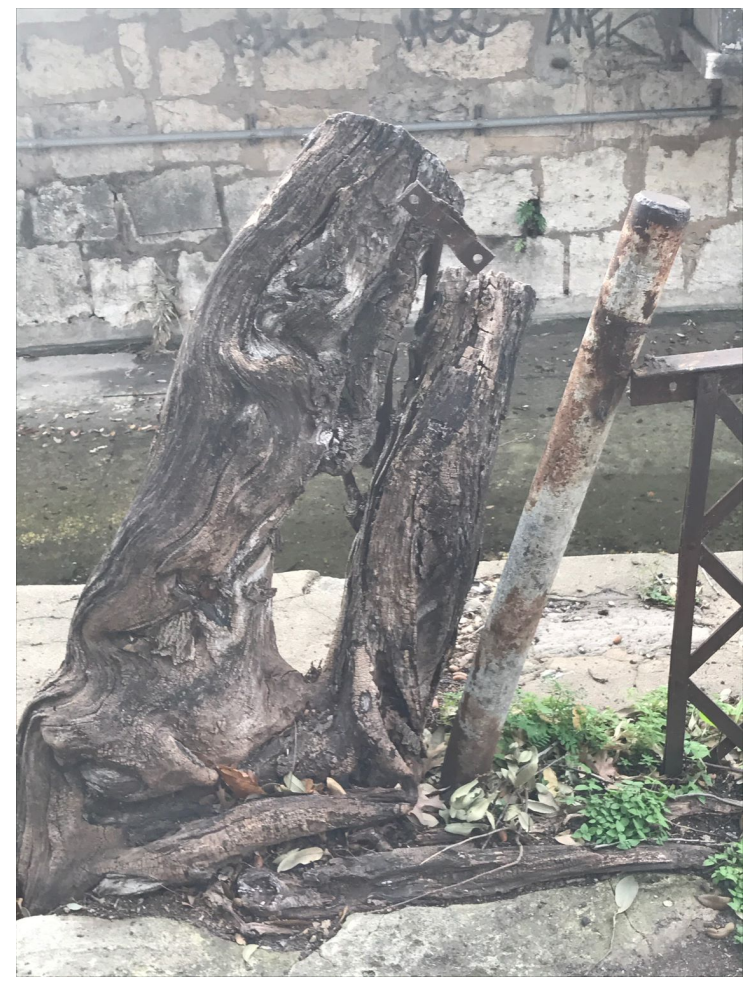

Fig. 1: "This picture represents the feeling of isolation and helplessness that rape victims feel when family, friends, and even the justice system turn their backs to them. They are forced to suffer in silence and live with the fact that their attacker remains free to target others" (Miguel). 
Figure 2 illustrates how another student believes we can transform rape culture:

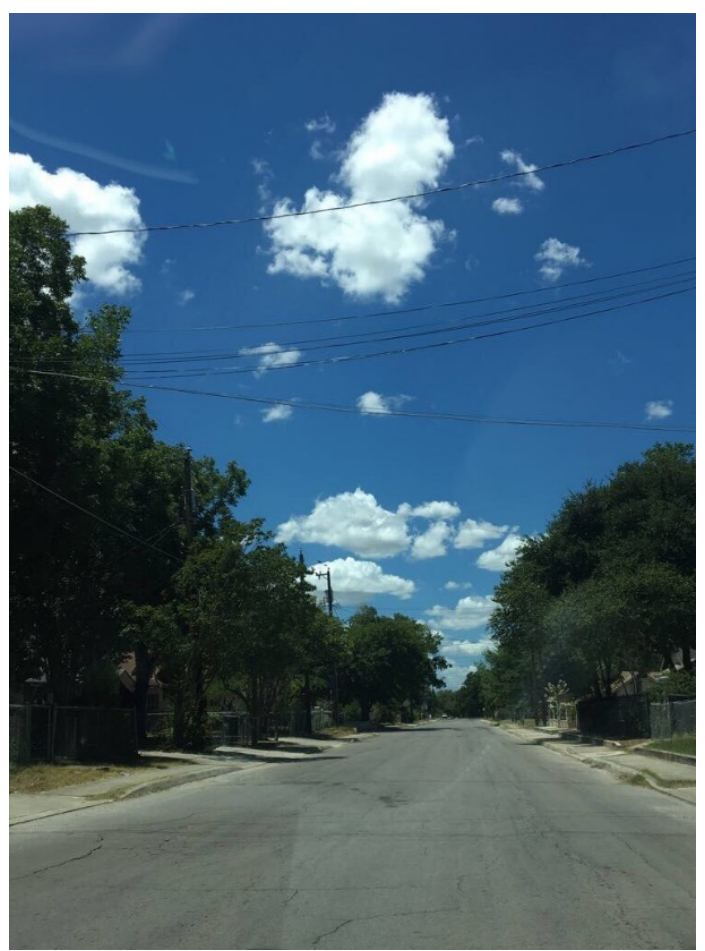

Fig. 2: "No matter how dark things get, there's a clear, blue sky on the other side of it all. Clear skies, clear roads, clear mind. We transform not by looking back, but by looking forward at the road ahead" (Ashley).

\section{Data Analysis}

The data for this study consisted of reflection papers submitted by the MSW students at the end of the semester. In analyzing the data, the researchers used grounded theory methods as described by Charmaz (2014). Grounded theory is a systematic and iterative set of methods aimed at constructing theories that are "grounded" in the data (Charmaz, 2014). For this study, line-by-line coding was used, which involved developing in-vivo codes of particularly rich segments of the data followed by focused coding, which consisted of recoding the data with conceptual codes that emerged from the line-by-line analysis. The focused coding process resulted in the emergence of three categories.

\section{Findings}

Our analysis of reflection papers yielded three categories that are: a) understanding the social worker's role in macro-level practice, b) enhancing learning of content, and c) engaging with the community.

\section{Understanding the Social Worker's Role in Macro-Level Practice}

Using ABR, specifically photovoice, to teach community practice resulted in the students understanding a fundamental role of social work in macro-level practice. Specifically, one role the students described 
learning is how to support the community members with generating and sharing local knowledge about community issues. In this case, the topic was on campus rape culture.

This experience also expanded skills I already have, including listening to the concerns of clients (participants) and finding innovative ways to engage the community, as well as utilizing careful planning of an outreach event, and relying on resilience when the best laid plans fell through. More importantly, I realize not to take lightly my influence as a social worker to impact the community in a positive way, a way that recognizes and understands that a collective voice has the power to make lasting changes. (Emerald)

Emerald articulated how her experience in the course facilitated a tangible understanding of the role of social work in macro practice. The course experience expanded skills that Emerald already possessed, particularly her ability to listen and engage the community through innovative methods. Emerald also mentioned the importance of creating a careful plan for the practice effort and to trust the resilience of her colleagues when plans fall through. Most relevant to this category is Emerald's understanding of her role (as a social worker) is to recognize and understand the collective voice of the community. It is through this recognition that a community gains the motivation necessary to create positive change.

Tabitha also viewed her experience with implementing a photovoice project as teaching her the importance of helping the community to articulate their lived experiences with stakeholders and the broader community.

Finally, what I also appreciate about the Photovoice is that it gives a voice to the community... I felt that this empowered our participants to speak their true feelings and have the opportunity to be heard by stakeholders and the community. I would like to replicate something similar to this in my future work, especially as I am sure I will be working with vulnerable populations who probably have little chance to make their voices heard. (Tabitha)

Based on this quotation, the course taught Tabitha a clear understanding of the roles social workers play in macro practice. Tabitha learned that one important role is to help the community locate mechanisms through which they can share their "true feelings" with stakeholders and the broader community. Tabitha also understands that another role is to help stakeholders to bear witness to the perceptions and experiences of community members. Learning these roles through the implementation of a photovoice project inspired Tabitha to say she would consider this approach in her future social work practice.

Many other students observed how the photovoice method facilitates the role of social work in macro practice. Students articulated how photovoice supports a community in sharing their perspectives on and experiences with an issue such as campus rape culture. "This project gave a great visual to their [the community] perceptions" (Crystal), "The impact of the focus group was a surprise for me. It turned out to be very informative and gave us insight to how students around campus and outside of the social work field view sexual assault" (Chandra), "It [photovoice] is a powerful tool for addressing sexual harassment as photos can reflect the victims' subjective experience (if a participant is a victim)... the images we received were very thoughtful and poignant" (Sarah). 
Using $A B R$, in particular, the photovoice method, as an approach for instruction on community practice illustrates an essential role that social workers must take when working at the macro level. Social workers focus on building relationships with communities and helping communities to identify and gather community resources to create change. An essential step in that process is giving the community a mechanism and space where they can demonstrate their lived experiences and local perspectives on given issues. MSW programs need to train social workers on how to support communities in collecting, organizing, and describing these perceptions and experiences. The data provided by the MSW students in this study illustrate how the students view photovoice as an effective method for providing this support.

\section{Enhancing Learning of Content}

Students learned to take on the role of a researcher, which included engaging in learning content and turning the research into action throughout all phases of the project. The photovoice method allowed them to understand the topic better through having a dialogue with their participants. As Paul stated, "the photovoice method allowed us to capture the varying perspectives of the photographs that the participants took. Hearing what the participants had to say about their pictures put into perspective on why this topic is so important," which is supported by another student's comment, "The viewing of the photos helped me to conceptualize what rape culture means" (Arianna).

Photovoice not only provided students with a greater understanding of rape culture and sexual assault, but also a noninvasive way to discuss the issue. Students described how using photos as a medium for addressing a sensitive topic was beneficial for making conversation about the topic less strenuous or easier. Tabitha described how using abstract images helped to create discussion about the issue,

...the photographs were not a directly worded opinion, but rather a symbolic picture. It felt easier to talk about the subject at the event... I learned through the use of photovoice the impact that a photograph can have; the interpretations of the symbolic image from not only the photographer, but the viewer, allowed for a unique dialogue to form. The photographs were a great conversation starter, as there was a wide array of questions that could be asked by looking at the images. (Tabitha)

She elaborated on the power of photos and how interpretation contributed to the discussion between the photographer and the viewer. This finding indicates that students learned about the value of symbolic images in creating dialogue.

Students expressed how the project allowed them to apply theories to practice. Throughout the semester, students engaged in class discussions and weekly readings centering around community practice theories and the photovoice method. As they learned the content, they were able to apply their knowledge in conducting the photovoice project and organizing the exhibit. One student described the effectiveness of course readings and discussion assignments in providing preparation to transform theory to practice, 
The course was designed in such a way that each week we were gradually exposed to theories and methods of community organizing through our course readings. These readings and the Blackboard discussions connected to them were directly related to tasks that our class was tackling that week in our project planning process. I found the connection between our weekly readings and project tasks to be extremely helpful throughout the process because the readings highlighted that there was logic and research behind what we were working on as a class. (Andrea)

Andrea emphasized the importance of the course structure in providing necessary tools each week that linked directly to project tasks. This structure provided students with a crucial grounding in understanding the role of course readings for the successful completion of each phase of the project. Students learned firsthand how to apply course content to practice. The course readings were instrumental in providing students with the background they needed to develop and implement the photovoice project. Students described the benefits of course content to real-world application. Michael stated, "I appreciated the experience of being able to think through the materials learned throughout the textbook and apply it to a real-world example." Another student expressed the importance of course content in planning and implementing the community event and the importance of class time to discuss the project,

The content of the class directly helped us to be able to create, build, and execute the event and make it successful. I believe that being able to use class time to talk about the event and being given examples were a lot of help. (Samantha)

Students were able to engage in learning through course content and examples as well as in-class discussion.

Learning course content provided the knowledge needed to complete the photovoice project. The content provided a foundation and gave students an appreciation for photovoice as an essential research method for addressing community issues and social problems affecting marginalized groups. One student expressed the unique ways in which photovoice as a research method can influence change,

I learned what photovoice is and how it can be implemented as a tool to collect information to bring light to an issue. Photovoice provides a visual that is hard to avoid or deny. We often hear that "a picture is worth a thousand words" and by utilizing photovoice as a research tool it gives a voice to the voiceless. It is a powerful and creative way to bring issues to light and affect change. Images transcend the barriers of language and it makes the issues harder to be ignored. (Luz)

Luz emphasized the power of photos and images to address community issues and transform language as well as the significance of learning about photovoice as a research tool. She expressed the value of using photos through photovoice as a method to bring awareness to sensitive and vital issues.

Other students expressed the value of photovoice and the focus group to reinforce course content. One student described how the photos and focus group provided an understanding of the readings.

It [photovoice] is a simple concept now that I have learned the process and for whom it is used. It was not until I saw the images created by our volunteers and the focus group session where they explained their photographs that I was beginning to understand our readings. (Ramon) 
This statement also highlights the reciprocal effect of how photos and the focus group enhanced learning.

Engaging in the various phases of the photovoice project allowed students to learn about the research role and the benefits of $A B R$ in addressing community issues. At each stage of the project, students learned content about sexual assault and rape culture on college campuses, photovoice as a research method, and the process of developing, planning, and implementing a community event to engage community stakeholders in dialogue. The firsthand experience of bringing knowledge and practice together in organizing a community through photovoice helped enhance student learning in the process. This finding adds another aspect to ABR's multi-faceted implications for community practice courses in social work education.

\section{Engaging With the Community}

The process of photovoice allowed students to understand the macro-level community practice aspect of social work by enabling them to engage in critical thinking. This finding is particularly important and significant as the experience led students to identify their role as a social worker. Photovoice allowed students to experience the macro-level community engagement, which led them to a better understanding of how to align critical thinking with the macro-level practice. Each phase of the project helped students gain a different perspective.

The focus group session of the photovoice phase provided an opportunity to hear the community members' perspectives. While community practice involves advocating for them, it is imperative to hear and understand the views of the community members for successful advocacy. Providing solutions for perceived problems or felt needs would be one approach. However, what constitutes success in these circumstances is to empower community members and allow them to contribute to the solution by giving them a voice. This finding was prevalent in the focus group phase as stated by one student:

The impact of the focus group was a surprise for me. It turned out to be very informative and gave us insight to how students around campus and outside of the social work field view sexual assault. It was insightful to hear their different perceptions of the sexual harassment. (Chandra)

By being a part of this project and working with undergraduate members of the university community, participants "moved" the larger community to address and center around a conflict that affects the entire campus. This effort is directly related to the purpose of the project and the photovoice method. The final exhibit allowed the MSW students, undergraduate participants, and community stakeholders to view others' perspectives and opinions as well as to engage in meaningful discussion. This exchange yielded new insights and ideas for transforming campus rape culture.

We empowered our participants to share their understandings and perceptions of sexual assault. They are members of the community, and it is imperative that their voices be heard. We gave them a unique platform to do this and it showed me how impacting an opportunity like that could be for my future clients. Finally, I feel that we empowered community members by providing a safe, nonjudgmental space to talk openly and honestly about sexual assault. 
Although the topic may have been difficult to talk about, we provided an environment which made it okay for them to speak up and share their own perceptions. (Tabitha)

Students also learned and experienced what it entails to organize a community. One participant clearly described the process regarding what is needed and what outcomes the students could expect:

Organizing a community around what it feels is their needs is important. Many times, there are instances when the social worker will go in with their own idea of what a community needs and that project will fail. Being able to ask questions and being open to those in the community will not only give you the report needed to gather participants but also at the same time educate the social worker on issues they may not have been aware of. (Ricardo)

Community engagement involves building relationships between the social workers, who are supporting the community, and stakeholder groups. Collaboration with community organizations to hold the exhibit was another aspect of community engagement that was mentioned by students: "Working with partner agencies is very crucial to providing services and resources to community members. They are just as equally important in dealing with a community awareness problem" (Sarah).

Overall, this project allowed the campus community to engage with the broader community by holding an exhibit of photographs produced. Using an innovative approach to address an important and, yet difficult, issue, helped students to connect with the roots of social work community practice while drawing attention to the problem and engaging with the broader community.

\section{Challenges With the Photovoice Process}

The current project was not without challenges which revolved around two main areas that are related to the nature of a research process, and the topic of this research project which was "transforming campus rape culture."

A primary challenge the students identified was with participant recruitment. As coresearchers, graduate students had difficulties in recruiting and retaining participants for the project. Considering the target participant profile, which was undergraduate students, one main problem in recruiting them was a commitment to the research process that involved multiple phases such as training and info session, focus group session, and the final exhibit at the end of the process.

One of the major challenges I noticed from the start was finding participants who were willing to commit their time and energy to the project. I felt that I had a tactical plan to recruit participants by sending out emails, detailing our project... No response was received... For the participants who were willing to participate, it was difficult for them to commit to attending the event and, more importantly, in my opinion, the focus group. (Ashley)

Given that the undergraduate and graduate students were located at two different campuses in the city, it was difficult to schedule meetings at mutually convenient times. "We wanted to recruit undergraduate students...but since we (the MSW program) were downtown, and many undergraduate students are at the main campus it was hard to recruit students" (Fonseca). 
As for the retention of participants, a challenge was that participants would show enthusiasm initially, but as the semester went on, they disappeared-they did not take the photos or did not respond to follow-up emails. This lack of involvement caused disappointment and discouragement among graduate students.

[I] did find the recruitment of a participant for the Photovoice project to be extremely difficult. Communication was one-way and I was not prepared for that. In the end, our participant did participate the night of the event, [but] without...participating in the focus group. I found this to be a personal challenge. My personal work ethic is set fairly high and the end results...were less than satisfactory in my opinion. (Ramona)

The second challenge was emotional dissonance over focusing on sexual violence. Given the sensitive nature of the topic, which was campus rape culture, it is understandable that participants would not feel comfortable participating or sharing experiences related to rape. The project addressed a sensitive issue, which not only led to difficulties in finding participants, but also created personal challenges for some graduate students who were leading the project. Dolores shared one example:

There were times I wished nothing more but to end the conversations. I am a survivor, and only one person knows my story and that was the result of being in this class; the re-traumatization became difficult to bear and I finally confided in my significant other. I did not want others in class to know, so it was a struggle to be there every day and talk about it at a deeper level.

Another student also had similar experiences to Dolores:

The topic of sexual assault and harassment is a sensitive topic for me. The entire project was difficult and brought many emotions to the surface. The day of the event was the worst for me. As I was driving to the event, I started to have a heavy feeling in my chest that lasted all night. After the event, I cried on my way home. (Luz)

Such negative experiences at a personal level helped graduate students to better understand their roles as social workers regarding how to approach vulnerable people they serve. Considering the sensitive nature of the topic, as social workers, graduate students recognized that they needed to be careful in their behaviors and choosing their words carefully so that they would not trigger adverse reactions or emotions in their participants. In addition to their role as social workers, graduate students were able to reflect on how negative feelings led to different movements and community initiatives and saw the value in it: "It seems as if that negative experience is what moves the efforts and the desire to change that keeps the movement alive" (Luz).

Though there are numerous benefits to using photovoice as a participatory action research project for addressing community issues, there are also challenges and limitations observed across studies. The challenges experienced in this project are not unique. Researchers note various issues that arise in project implementation and photo exhibit events. Challenges include time constraints, recruitment concerns, problems with participant involvement and attrition, sample size, ethical concerns, photo exhibit participation, limited resources, and student project issues. 
Time constraints affect photovoice research in several ways. The length of projects can affect participant attrition (Capous-Desyllas \& Forro, 2014; Baker \& Wang, 2006; Budig et al., 2018). Time limitations influence the quality of photos when participants feel pressed and are unable to produce effective and meaningful images to identify and capture community issues (Findholt, Michael, \& Davis, 2010; Capous-Desyllas \& Forro, 2014). Lack of meaningful engagement of participants, and lack of clarity on participant responsibilities and obligations, can compete with data collection timelines and can complicate focus group sessions, and exhibit participation (Capous-Desyllas \& Forro, 2014; Budig et al., 2018; Johnston, 2016). These issues affect the recruitment and retention of participants. Also, recruitment of participants who belong to groups affected by social stigma may require more time to create trust and rapport building (Bukowski \& Buetow, 2011; Capous-Desyllas \& Forro, 2014; Povee, Bishop, \& Roberts, 2014).

There are also ethical challenges. Prime issues are related to confidentiality, which complicates the allowable content of photographs. Using images of people, protections of privacy, intrusions of public space, use of personal likeness for commercial gain, and presenting a person in a false light (Goodhart et al., 2006) are areas of concern in a photovoice project. Other ethical concerns center on the use of photovoice in community-based participatory research (CBPR). CBPR values the involvement of multiple stakeholder groups, which can be challenging. Three areas that involve ethical sensitivitymaking sure to engage decision-makers in projects, managing the sorting and analyzing the abundance of data collected, and accurately presenting photos and narratives-are most important to participants (Wang \& Burris, 1997: Wang \& Redwood-Jones, 2001; Latz, 2017). Also, researchers note conflict with the power and control dynamic between the researchers and participants when using photovoice (Povee et al., 2014). In an effort to diminish the power and control dynamics, researchers tend to be more friendly and less formal with participants to pacify power and inequality (Capous-Desyllas \& Forro, 2014). Ethical considerations also include managing participant expectations of definitive change in issues the community identified (Wang \& Redwood-Jones, 2001) and negotiating whether participants want to be in the position of being agents of social change (Latz, 2017).

Incorporating a photovoice exhibit at the end is a key aspect of a photovoice project with the purpose of influencing policy makers and other stakeholders who interacted with the work. If these actors are not invited or fail to attend the exhibit, an opportunity is missed for a dialogue (Capous-Desyllas \& Forro, 2014). A photovoice exhibit is different from a photography exhibit as it is about stories told through photographs and narratives - the intention is to raise the critical consciousness of people who observe the exhibit (Latz, 2017). Given this intention, educators must consider how the photos and narratives interfere with or expand attendees' understanding of the issue presented. Thus, it is important to assess community and individual impact adequately (Baker \& Wang, 2006; Pruitt et al., 2016; Seitz et al., 2012).

Researchers noted additional challenges using photovoice methodology with undergraduate students. Findholt and colleagues (2010) noted the following: 1) inadequate photography training, 2) inability for students to conceptualize themes and orient to the bigger picture, and 3) difficulty identifying community issues as student participants focused on photos of family and friends. Other challenges observed by researchers included students struggling to locate the decision makers to participate in the project and 
classroom projects where teachers did not trust undergraduate student researchers to complete tasks (Warne, Snyder, \& Din, 2012).

\section{Discussion}

Our findings provided evidence of the characteristics of using photovoice to teach community practice. While we identified three categories that emerged from the data, they overlap and complement each other to present the big picture. Incorporating a photovoice project as part of the coursework provided an opportunity to take the classroom into the community. This practice had multiple implications for the community engagement aspect of social work. As the social work profession entails working within communities, it is vital to equip future social workers with skills and tools they need in practice, which includes empowering community members by giving them a voice, listening to and hearing their perspectives, organizing them, and advocating for them to make a positive impact.

While different fields use $A B R$ in various ways, incorporating $A B R$ into social sciences has been slow. Previous research illustrates examples of how to use ABR, such as photovoice, in classroom practices, but most of the time this work is limited to the classroom setting (Schell et al., 2009; Tracey, 2009). However, using creative approaches such as ABR to teach community practice, gives the students the opportunity to share the coursework and ABR results with the public, which makes student learning authentic. Considering the nature of social work, which addresses community needs and strengths, it is essential to share the results of the coursework with the public because it engages students in higher-level learning. Doing exhibits or events that are open to the public gives students the opportunity to interact with community members, participate in public dialogue, and produce authentic learning through the experience of presenting their work (Massengale, Strack, Orsini, \& Herget, 2016).

This study is significant in multiple ways:

(i) social work students had hands-on experience in conducting photovoice research and engaging with the community;

(ii) they applied theory to practice;

(iii) the project culminated with a public event that had an impact on the students, the project participants, and the community members who attended; and,

(iv) the arts-based approach acted as the tool to link the communities of the campus and the public.

We believe that $A B R$ as a pedagogical tool has great potential to enhance student learning in community practice in the social work field. Integration of photovoice in community practice curriculum in social work programs allows students to engage in their education and the community, start to see their

environment or the subject matter from a different perspective, and increase subject awareness among local community members (Massengale et al., 2016; Goodhart et al., 2006). 


\section{References}

Baker, T. A., \& Wang, C. C. (2006). Photovoice: Use of a participatory action research method to explore the chronic pain experience in older adults. Qualitative Health Research, 16(10), 1405-1413. doi:10.1177/1049732306294118.

Barron, C., \& Taylor, B. J. (2010). 'The rights tools for the right job: Social work students learning community development'. Social Work Education, 29(4), 372-385.

Budig, K., Diez, J., Conde, P., Sastre, M., Hernán, M., \& Franco, M. (2018). Photovoice and empowerment: Evaluating the transformative potential of a participatory action research project. BMC Public Health, 18, 432. doi:0.1186/s12889-018-5335-7.

Bukowski, K., \& Buetow, S. (2011). Making the invisible visible: A photovoice exploration of homeless women's health and lives in central Auckland. Social Science and Medicine, 72, 739-746.

Capous-Desyllas, M., \& Forro, V. A. (2014) Tensions, challenges, and lessons learned: Methodological reflections from two photovoice projects with sex workers. Journal of Community Practice, 22(1-2), 150-175. doi:10.1080/10705422.2014.901269.

Charmaz, K. (2014). Constructing grounded theory. London: Sage Publications.

Chio, V. M., \& Fandt, P. M. (2007). Photovoice in the diversity classroom: Engagement, voice, and the 'Eye/I' of the camera. Journal of Management Education, 31(4), 494-504.

Cooper, C., Sorensen, W., \& Yarbrough, S. (2017). Visualizing the health of communities: Using photovoice as a pedagogical tool in the college classroom. Health Education Journal, 76(4), 454-466.

Council on Social Work Education. (2015). Educational policy and accreditation standards.

Alexandria, VA: Author. Retrieved from http://www.cswe.org/File.aspx?id=81660

Dixon, J., \& Hoatson, L. (1999). 'Retreat from within: Social work's faltering commitment to community work'. Australian Social Work, 52(2), 3-9.

Findholt, N.E., Michael, Y. L., \& Davis, M.M. (2010) Photovoice engages rural youth in childhood obesity prevention. Public Health Nursing, 28(2), 186-192.

Finley, S. (2008). Arts-based research. In J.G. Knowles \& A. L. Cole (Eds.), Handbook of the arts in qualitative research: Perspectives, methodologies, examples, and issues (pp. 71-81). Thousand Oaks, CA: Sage.

Goodhart, F. W., Hsu, J., Baek, J. H., Coleman, A. L., Maresca, F. M., \& Miller, M. B. (2006). A view through a different lens: Photovoice as a tool for student advocacy. Journal of American College Health, 55(1), 53-56.

Guba, E. G., \& Lincoln, Y. S. (1994). Competing paradigms in qualitative research. In N. K. Denzin \& Y. S. Lincoln (Eds.), Handbook of qualitative research (pp. 105-117). Thousand Oaks, CA: Sage.

Holley, L. C., Risley-Curtiss, C., Stott, T., Jackson, D. R., \& Nelson, R. (2007). 'It's not scary': Empowering women students to become researchers. Affilia: Journal of Women and Social Work, 22(1), 99-115.

Holm, G., Sahlström, F., \& Zilliacus, H. (2018). Arts-based research. In P. Leavy (Ed.), Handbook of arts-based research (pp. 311-336). New York, NY: Guilford Press. 
Johnston, G. (2016). Champions for social change: Photovoice ethics in practice and "false hopes" for policy and social change. Glob Public Health, 11, 799-811.

Latz, A. O. (2017). Photovoice research in education and beyond. New York, NY: Routledge.

Leavy, P. (2009). Arts-based research as a pedagogical tool for teaching media literacy: Reflections from an undergraduate classroom. LEARNing Landscapes, 3(1), 225-242.

Leavy, P. (2018). Introduction to arts-based research. In P. Leavy (Ed.), Handbook of arts-based research (pp. 3-22). New York, NY: Guilford Press

Lucero, J. L. (2015). Engaging undergraduate social work students in community-based research: Developing research skills through hands-on learning. Council on Undergraduate Research, 35(4),18-24.

Maistry, M. (2012). Community engagement, service learning and student social responsibility: Implications for social work education at South African universities: A case study of the University of Fort Hare. Social Work/Maatskaplike Werk, 48(2), 142-158.

Massengale, K. E. C., Strack, R. W., Orsini, M. M., \& Herget, J. (2016). Photovoice as pedagogy for authentic learning: Empowering undergraduate students to increase community awareness about issues related to the impact of low income on health. Pedagogy in Health Promotion, 2(2), 117-126.

McNiff, S. (2018). Philosophical and practical foundations of artistic inquiry. In P. Leavy (Ed.), Handbook of arts-based research (pp. 22-36). New York, NY: Guilford Press.

Minkler, M. (2000). Using participatory action research to build healthy communities. Public Health Reports, 115(2-3), 191-197. doi:10.1093/phr/115.2.191.

Ohmer, M. L., Reisch, M., \& Weil, M. (2013). The handbook of community practice. Thousand Oaks, CA: SAGE Publications.

Povee, K., Bishop, B. J., \& Roberts, L. D. (2014). The use of photovoice with people with intellectual disabilities: Reflections, challenges, and opportunities. Disability \& Society, 29(6), 893-907. doi:10.1080/09687599.2013.874331.

Pruitt, A.S., Barile, J. P., Ogawa, T. Y., Peralta, N., Bugg, R., Lau, J., et al. (2016). Housing first and photovoice: Transforming lives, communities, and systems. American Journal of Community Psychology, 61, 104-117. doi:10.1002/ajcp.12226.

Schell, K., Ferguson, A., Hamoline, R., Shea, J., \& Thomas-Maclean, R. (2009). Photovoice as a teaching tool: Learning by doing with visual methods. International Journal of Teaching and Learning in Higher Education, 21(3), 340-352.

Seitz C. M., Strack, R. W., Rice, R., Moore, E., DuVall, T., \& Wyrick, D. L. (2012). Using the photovoice method to advocate for change to a campus smoking policy. Journal of American College Health, 60(7), 537-540. doi:10.1080/07448481.2012.688781.

Tracey, S. (2009). Crossing thresholds and expanding conceptual spaces: Using arts-based methods to extend teachers' perception of literacy. LEARNing Landscapes, 3(1), 243-262.

Vygotsky, L. S. (1978). Mind in society: The development of higher psychological processes. M. Cole et al. (Eds.). Cambridge, MA: Harvard University Press. 
Wang, C., \& Redwood-Jones, Y.A. (2001). Photovoice ethics: Perspectives from Flint photovoice. Health Education and Behaviour, 28, 560-572.

Wang, C.C., \& Burris, M. A. (1997). Photovoice: Concept, methodology, and use for participatory needs assessment. Health Education and Behavior, 24, 369-387. doi:10.1177/109019819702400309

Wang, C.C. (1999). Photovoice: A participatory action research strategy applied to women's health. Journal of Women's Health, 8(2), 185-192. doi:10.1089/jwh.1999.8.185

Wang, C.C., Morrel-Samuels, S., Hutchison, P. M., Bell, L., \& Pestronk, R. M. (2004). Flint photovoice: Community building among youths, adults, and policymakers. American Journal of Public Health, 94(6), 911-913.

Warne, M., Snyder, K., \& Din, K. J. (2012). Photovoice: An opportunity and challenge for students' genuine participation. Health Promotion International, 28(3), 299-310. doi:10.1093/heapro/das011.

Weber, S. (2008). Visual images in research. In J. G. Knowles \& A. Cole (Eds.), Handbook of the arts in qualitative research (pp. 41-53). Los Angeles, CA: Sage.

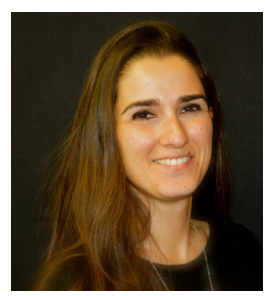

Inci Yılmazlı Trout is a doctoral student in education at the University of the Incarnate Word in San Antonio, TX. Her research interests include research methodology, particularly arts-based research and action research, doctoral education, doctoral student experiences, and identity development. İnci is the recipient of the Frost Play Research Collection Fellowship for 2017-2018, and the UIW Excellence in Inquiry Award in 2018.

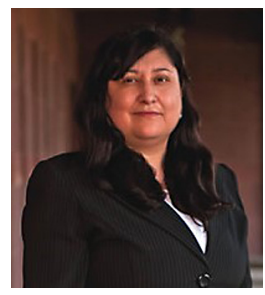

Beatrix Perez is an Assistant Professor of Sociology at San Antonio College. Her research interests include sociology of education, foster care, homelessness, social capital, arts-based research, and qualitative research methodologies. She has published work on the residential instability of youth aging out of the foster care system, educational experiences of Latino youth in foster care placements, structural barriers to Latino educational achievement, and the impact of poverty and homelessness on education. She has worked on various grants including the U.S. Department of Housing and Urban Development (HUD), the United Way, and the University of Texas Health Science Center. Beatrix is a recipient of the National Institute for Staff and Organizational Development (NISOD) Teaching Excellence Award for 2019.

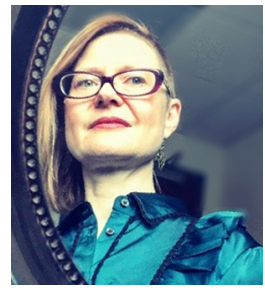

M. Candace Christensen is an Assistant Professor of Social Work at the University of Texas at San Antonio. Candace's research centers on using feminist and arts-based methodologies to address gender-based violence (GBV). Candace was awarded the Feminist Manuscript Scholarship Award for 2013 from the Council on Social Work Education and the UTSA Presidential Achievement Award for Excellence in Teaching in 2018. 